\title{
Future therapy for hepatitis B virus infection
}

\author{
Masahito Minami $^{1,2}$
}

Received: 1 July 2015/ Accepted: 12 July 2015/Published online: 12 August 2015

(C) Springer Japan 2015

\begin{abstract}
We can now control hepatitis B virus infection by continuously administering nucleoside and nucleotide analogues such as entecavir and tenofovir. These drugs are generally safe and sufficiently effective, but future drugs are needed that can show off-treatment efficacy-in other words, eradication of latent hepatitis B virus DNA (covalently closed circular DNA) in the hepatocytes. This article is an overview of new drugs under development and some novel strategies to inhibit hepatitis B virus proliferation.
\end{abstract}

Keywords Nucleoside analogue $\cdot$ Cyclosporine APOBEC $3 \cdot$ RNA interference $\cdot$ Peptide vaccine

\section{Introduction}

Nucleoside and nucleotide analogs (NAs) are potent orally administered inhibitors of hepatitis B virus (HBV) replication. In Japan, four drugs-lamivudine, adefovir, entecavir, and tenofovir-are approved for use in treating HBV infection. The treatment efficacies of these drugs are excellent, but relapses after drug cessation are common [1, 2]. Thus, the duration of the various NAs tends to be long and often infinite, because NAs do not inhibit either HBV's covalently closed circular DNA (cccDNA) or viral protein production. Prolonged treatment can result in the emergence of drug resistance, particularly in cirrhotic and

Masahito Minami

minami@koto.kpu-m.ac.jp

Aiseikai Yamashina Hospital, Kyoto, Japan

2 Molecular Gastroenterology and Hepatology, Department of Medicine, Graduate School of Medicine, Kyoto Prefectural University of Medicine, Kyoto, Japan immune-suppressed patients [3, 4]. Another problem related to NA therapy is its unknown safety profile, particularly when administered for long periods [5]. NAs may have an inhibitory effect on host DNA polymerase, particularly mitochondrial polymerase. Indeed, clevudine, a nucleoside analog approved only in Korea, has been reported to cause myopathy [6].

Another currently used therapy for HBV infection is interferon. Interferon has both antiviral and immunemodulatory effects against HBV. When it is effective, the durability of treatment responses, such as hepatitis $\mathrm{B}$ e antigen ( $\mathrm{HBeAg}$ ) seroconversion and negative DNA test results, are reported to be superior to those of lamivudine [7]. Moreover, the duration of interferon therapy is finite and rarely induces drug resistance. Problems related to interferon therapy are low response rate, considerable side reactions, and the parenteral route of administration [8]. Thus, we can now control HBV infection by indefinitely administering NAs, but cure and eradication of HBV are still difficult and almost unachievable using current therapeutics. In this review, the author introduces new therapeutic strategies and drugs under clinical trials for $\mathrm{HBV}$ other than NAs and interferon (Table 1). Many of these drugs might theoretically overcome the limitation of current HBV therapies, and some encouraging results are being accumulated.

\section{HBV life cycle}

Each step of HBV's proliferation cycles can be a target for antivirals. Here is an overview of the HBV life cycle [9]. HBV binds to the surface receptors of hepatocytes and is internalized. Virions are decapsulated, and viral core particles, including viral DNAs, are carried into the nucleus. 
Table 1 Future drugs for treating hepatitis B virus infection

\begin{tabular}{|c|c|c|c|}
\hline & Note & Route of administration & Development stage \\
\hline \multicolumn{4}{|l|}{ Entry inhibition } \\
\hline Myrcludex B & Synthetic lipoprotein & Daily s.c. & Phase II \\
\hline Rep2139 & Nucleic acid polymer & Weekly i.v. & Phase II \\
\hline CPI-431-32 & Cyclophilin inhibitor & & Preclinical \\
\hline SCYX1454139 & Cyclophilin inhibitor & & Preclinical \\
\hline \multicolumn{4}{|l|}{ Capsid inhibitor } \\
\hline NVR3-778 & Assembly inhibition & p.o. & Phase IIa \\
\hline Bay41-4109 and its derivative GLS4 & Assembly inhibition & p.o. & Phase I and preclinical \\
\hline \multicolumn{4}{|l|}{ Immunomodulator } \\
\hline SB9200 & Activator of RIG-I and NOD2 & p.o. & Phase II \\
\hline Birinapant & Induction of cell apoptosis & Weekly i.v. & Phase I/IIa \\
\hline GS9620 & TLR7 agonist & p.o. & Phase II \\
\hline CYT107 & Interleukin-7 & Injection & Phase I/IIa \\
\hline \multicolumn{4}{|l|}{ Therapeutic vaccine } \\
\hline $\mathrm{ABX} 203$ & & & Phase IIb/III \\
\hline GS4774 & & s.c. & Phase II \\
\hline TG1050 & & s.c. & Phase I \\
\hline \multicolumn{4}{|l|}{ RNA interference } \\
\hline ARC520 & & i.v. & Phase II/III \\
\hline TKM-HBV & & i.v. & Phase I \\
\hline ALN-HBV & & & Preclinical \\
\hline \multicolumn{4}{|l|}{ Others } \\
\hline Nitazoxanide $\left(\right.$ Alinia $\left.^{\circledR}\right)$ & & p.o. & Preclinical \\
\hline
\end{tabular}

Development stage was obtained from Hepatitis B Foundation (http://www.hepb.org/professionals/hbf_drug_watch.htm) as of June 2015 s.c. subcutaneous, i.v. intravenous, p.o. per os

In the nucleus, viral DNAs are repaired to form a cccDNA from which viral mRNAs are transcribed and viral proteins required for reproduction of an $\mathrm{HBV}$ virion are translated. Viral surface, core, and polymerase proteins are essential for $\mathrm{HBV}$ proliferation and thus can be good targets for antiviral drugs. Viral pre-genomic RNAs are also transcribed from cccDNA and assemble with viral core proteins. In these viral progeny capsids, pre-genomic RNAs are reverse-transcribed to the HBV DNAs using a viral polymerase. The resulting cores are enveloped with surface proteins and transported to the cell membrane and then bud from the hepatocyte. Targets for antiviral proliferation are summarized in Fig. 1.

HBV DNA is integrated into the host genome during this life cycle, but the integrated DNA is defective and not replication-competent. In contrast, cccDNAs are stable and persist even after transient self-limiting infection. HBV reactivation can occur from latently infected HBV when the host immune systems are highly suppressed [10]. Inhibition of reactivated proliferation from cccDNA is important for curative treatment and eradication of $\mathrm{HBV}$.

\section{Viral entry inhibitors}

The entry of HBV into the cell occurs, at least, via attachment of the viral surface protein to heparan sulfate proteoglycans on hepatocytes and binding of viral particles to its recently identified receptor sodium taurocholate cotransporting polypeptide (NTCP) [11].

Myrcludex-B is a synthetic lipopeptide that mimics HBV preS1 protein [12]. It binds to the NTCP receptor and inactivates its receptor function, inhibiting HBV cell entry [13].

Cyclosporin $\mathrm{A}$ is an immunosuppressive agent, but it has been revealed to have the potential to suppress replication of various viruses, including the human immunodeficiency virus (HIV), hepatitis $\mathrm{C}$ virus (HCV), and influenza virus [14]. In most cases, the antiviral effects of cyclosporin A can be attributed to its inhibition of cyclophilin, which is believed to catalyze conformational changes in various proteins including viral ones. However, cyclosporin A inhibited HBV entry into cultured hepatocytes via NTCP inhibition but independently of cyclophilin. Cyclosporin A and its derivatives are thus candidates for novel HBV entry 
Fig. 1 Steps of the hepatitis B virus life cycle that can be a target for antivirals

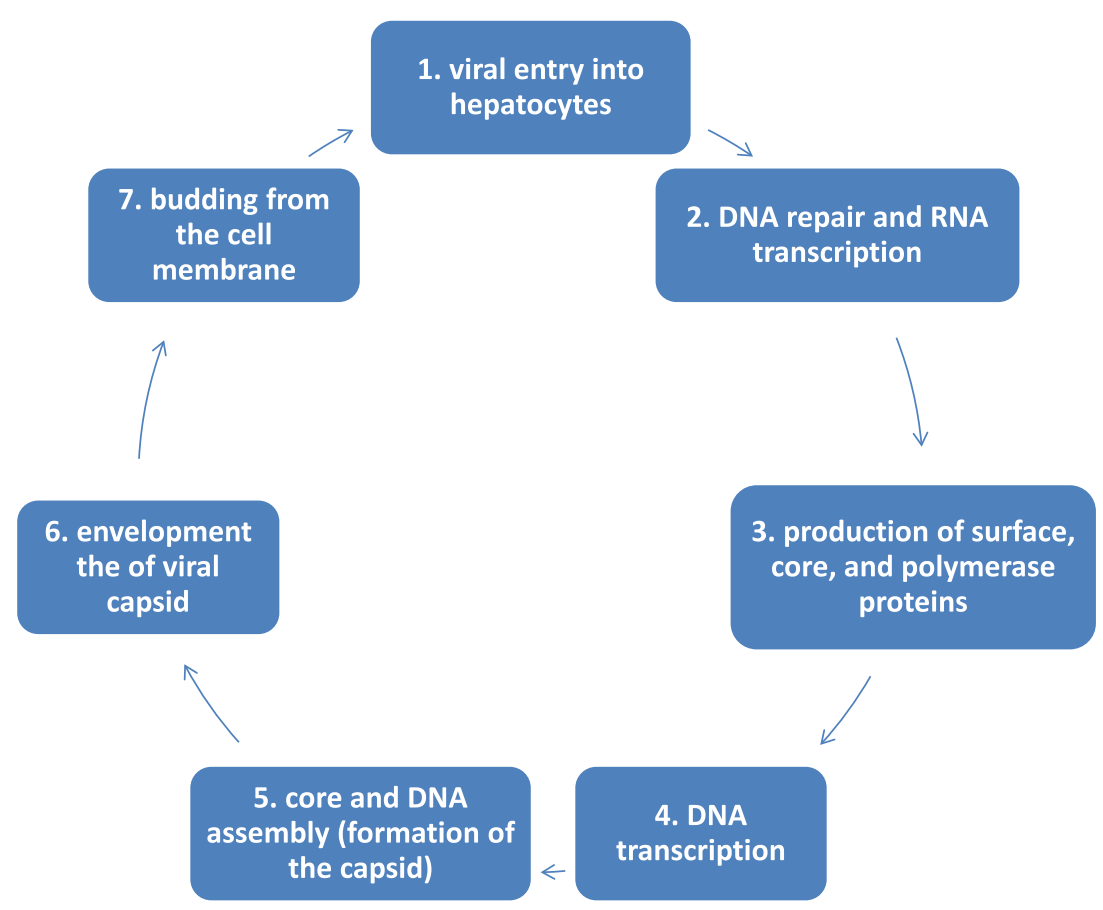

inhibitors. CPI-431-32 and SCYX1454139 are cyclosporin A derivatives that exhibit anti-HBV entry effects [14, 15].

Rep 2139, a nucleic acid polymer (NAP), has been shown to inhibit duck HBV infection in vitro and in vivo [16]. NAPs are novel, broad-spectrum antiviral compounds that use the sequence-independent properties of phosphorothioate oligonucleotides (PS-ONs) as amphipathic polymers to block amphipathic interactions involved in viral attachment. They also have been shown to block the assembly of HBV surface proteins, thereby inhibiting the release of infective virions from infected hepatocytes [17]. In its phase II study, Rep 2139 has shown remarkable antiviral effects. Twelve chronic hepatitis B patients were dosed with Rep 2139. After 20-24 weeks of treatment, 8 of 12 patients showed undetectable HBV RNA in sera. These 8 responders received addon peginterferon $\alpha$ and/or thymosin $\alpha$, and 4 of 8 achieved loss of HBsAg and HBsAb seroconversion [18].

\section{Capsid inhibitors}

Bay 41-4109 is a new compound shown to inhibit HBV DNA replication by destabilizing core particle assembly and disrupting existing capsids in vitro $[19,20]$. Bay 41-4109 was found to be hepatotoxic to rats at high doses, and GLS4, a compound related to Bay 41-4109, was found to be as potent as Bay 41-4109 [20].

NVR 3-778 is a small molecule that inhibits assembly of HBV core and capsid proteins. It reduced serum HBV DNA below the limit of quantitation in humanized mouse models, either alone or in combination with entecavir or interferon [21].

\section{Nucleoside and nucleotide analogues}

Drugs of this category are the first direct-acting antivirals against HBV replication and are widely used. They are well tolerated and continuously suppress viral proliferation on treatment. However, they are less effective against HBsAg and cccDNA, resulting in reactivation of HBV after cessation of the drugs. Novel NAs with stronger antiviral effects, higher barriers to drug resistance, and fewer side effects are under development.

\section{Immunomodulators}

SB9200 is a prodrug of the dinucleotide antivirals. It is thought to modulate host immune response to viral infection and activate host proteins RIG-1 and NOD2. Oral administration of SB9200 in woodchucks with chronic woodchuck hepatitis B (WHBV) infection reduced serum levels of WHBV DNA and surface antigen [22].

Birinapant is a bivalent small-molecule compound that mimics the peptide motif of the second mitochondriaderived activator of caspase (SMAC). It binds to apoptosis inhibitors such as cIAP1, cIAP2, and XIAP, thereby inducing cell death in cancer cells and viral-infected cells [23].

GS9620 is a Toll-like receptor-7 agonist and can be administered orally, resulting in induction of interferonstimulated genes (ISG). Oral administration of GS9620 in chimpanzees chronically infected with HBV demonstrated a decline in serum levels of HBV DNA [24]. GS9620, in its 
phase I study, was orally administered to chronic hepatitis B patients [25]. It was safe, well tolerated, and associated with induction of peripheral ISG 15 production in the absence of significant systemic interferon $\alpha$ levels or related symptoms. However, no decrease in serum HBsAg or HBV DNA levels was observed in that regimen.

CYT107 is a recombinant human interleukin-7 [26]. Interleukin-7 plays a central role in T-cell development-in particular, CD4+ $\mathrm{T}$ cells. It can be expected to activate an immune response to cancer cells and viral-infected cells. Clinical trials are ongoing in various diseases such as melanoma, kidney cancer, and $\mathrm{HIV}, \mathrm{HCV}$, and $\mathrm{HBV}$ infection [27].

\section{Therapeutic vaccines}

GS-4774 is a recombinant, heat-killed, yeast-based vaccine engineered to express $\mathrm{HBV}$-specific antigens $\mathrm{HBs}$, $\mathrm{HBc}$, and HBx [28]. It was safe and well tolerated in healthy human participants.

TG1050 is a non-replicative adenovirus serotype 5 encoding a unique large fusion protein composed of a truncated HBV core, a modified HBV polymerase, and two envelope domains [29]. TG1050 demonstrated HBsAg seroconversion in persistently infected mouse models [30].

ABX203 is a therapeutic vaccine composed of two recombinant proteins from viral surface antigen and core antigen (http://www.abivax.com/en/com-abivax-title-med ias/news-events/press-releases/74-abivax-recruits-first-patientin-a-pivotal-phase-iib-iii-clinical-trial-with-abx203-a-novelimmunotherapy-against-chronic-hepatitis-b.html).

\section{RNA interference}

ARC520 is a short interfering RNA (siRNA)-based therapeutic efficiently delivered into the cytoplasm of hepatocytes [31]. It showed decreased levels of HBsAg and HBV DNA in mouse and chimpanzee models (http://www.arro wheadresearch.com/programs/ARC-520).

TKM-HBV is a novel lipid nanoparticle-formulated RNAi therapy that uniquely targets three highly conserved regions of the HBV. In preclinical studies, it showed decreased levels of serum and intrahepatic viral antigens and DNA (http://investor.tekmirapharm.com/releasedetail. cfm?releaseid $=876403)$.

ALN-HBV is also an RNAi targeted to HBV, and it showed decreased levels of HBV antigens in chimpanzee models (http://www.alnylam.com/web/assets/ALNY-Con jugates-HBVprogram-TIDES-May2014.pdf).

\section{Others}

Nitazoxanide $\left(\right.$ Alinia $^{\circledR}$ ) is the first thiazolide, originally developed for the treatment of Cryptosporidium parvum infection [32]. In preliminary studies, nitazoxanide resulted in loss of $\mathrm{HBeAg}$ in the majority of patients and in loss of HBsAg in approximately a quarter of patients.

Recently, Lucifora et al. [33] demonstrated that interferon $\alpha$ and lymphotoxin $\beta$ could activate APOBEC3A and APOBEC3B cytidine deaminases and degrade $\mathrm{HBV}$ cccDNA in the presence of $\mathrm{HBV}$ core protein. As we know, interferon $\alpha$ is currently used for the treatment of chronic hepatitis $\mathrm{B}$, but its efficacy is still limited. Thus, Lucifora et al. indicated that targeting lymphotoxin $\beta$ and consequently cytidine deaminase activation can be a potential new therapeutic approach to reducing intrahepatic HBV cccDNA, leading to a cure of $\mathrm{HBV}$ infection.

\section{Conclusion and perspectives}

As with treatment of HIV and HCV, it is better to use two or three drugs with different mechanisms of action to avoid viral resistance [34-36]. As for HBV, we can use only two categories of drugs in Japan: several NAs, which are classified as polymerase inhibitors, and interferons, which are classified as host immune modulators. We can prevent NA-resistant HBV by replacing or adding different nucleoside or nucleotide analogues; however, direct-acting antivirals with different mechanisms of action are needed.

As described above, various drugs in new categories are currently under development. They seem to be effective with HBV infection by single administration, but we can also anticipate their additive effects with currently used NAs and interferon. Although some clinical data are available that show antiviral efficacy of newly developing drugs, those drugs need to show high safety profiles in clinical settings before approval. Currently used NAs such as entecavir and tenofovir are very safe and sufficiently effective when continuously administered. We are now searching for strategies that allow eradication or off-treatment inhibition of HBV replication. Those drugs must be as safe as NAs; otherwise, it might be better to adhere to continuous NA administration.

\section{Compliance with ethical standards}

Conflict of interest Masahito Minami declares that there is no conflict of interest. 


\section{References}

1. Liaw YF, Leung NW, Chang TT, Guan R, Tai DI, Ng KY, et al. Effects of extended lamivudine therapy in Asian patients with chronic hepatitis B. Gastroenterology. 2000;119:172-80.

2. Yao GB, Cui ZY, Wang BE, Yao JL, Zeng MD. A 3-year clinical trial of lamivudine in treatment of patients with chronic hepatitis B. Hepatobiliary Pancreat Dis Int. 2004;3:188-93.

3. Chang TT, Lai CL, Chien RN, Guan R, Lim SG, Lee CM, et al. Four years of lamivudine treatment in Chinese patients with chronic hepatitis B. J Gastroenterol Hepatol. 2004;19:1276-82.

4. Lok AS, Lai CL, Leung N, Yao GB, Cui ZY, Schiff ER, et al. Long-term safety of lamivudine treatment in patients with chronic hepatitis B. Gastroenterology. 2003;125:1714-22.

5. Fontana RJ. Side effects of long-term oral antiviral therapy for hepatitis B. Hepatology. 2009;49:S185-95.

6. Seok JI, Lee DK, Lee CH, Park MS, Kim SY, Kim HS, et al. Long-term therapy with clevudine for chronic hepatitis B can be associated with myopathy characterized by depletion of mitochondrial DNA. Hepatology. 2009;49:2080-6.

7. van Nunen AB, Hansen BE, Suh DJ, Lohr HF, Chemello L, Fontaine $\mathrm{H}$, et al. Durability of $\mathrm{HBeAg}$ seroconversion following antiviral therapy for chronic hepatitis B: relation to type of therapy and pretreatment serum hepatitis B virus DNA and alanine aminotransferase. Gut. 2003;52:420-4.

8. European Association for the Study of the Liver. EASL clinical practice guidelines: management of chronic hepatitis B. J Hepatol. 2009;50:227-42.

9. Ganem D, Prince AM. Hepatitis B virus infection-natural history and clinical consequences. N Engl J Med. 2004;350:1118-29.

10. Lok ASF, McMahon BJ. Chronic hepatitis B: update 2009. Hepatology. 2009;50:661-2.

11. Lempp FA, Urban S. Inhibitors of hepatitis B virus attachment and entry. Intervirology 2014;57:151-7.

12. Petersen J, Dandri M, Mier W, Lutgehetmann M, Volz T, von Weizsacker F, et al. Prevention of hepatitis B virus infection in vivo by entry inhibitors derived from the large envelope protein. Nat Biotechnol. 2008;26:335-41.

13. Ni Y, Lempp FA, Mehrle S, Nkongolo S, Kaufman C, Falth M, et al. Hepatitis B and D viruses exploit sodium taurocholate cotransporting polypeptide for species-specific entry into hepatocytes. Gastroenterology. 2014;146:1070-83.

14. Watashi K, Urban S, Li W, Wakita T. NTCP and beyond: opening the door to unveil hepatitis B virus entry. Int J Mol Sci. 2014;15:2892-905.

15. Gallay P, Chatterji U, Bobardt M, Ure D, Trepanier D, Foster R, et al. Novel cyclophilin inhibitor CPI-431-32 shows broad spectrum antiviral activity by blocking replication of HCV, HBV, and HIV-1 viruses. J Hepatol. 2015;62:S677 (Abstract P0890).

16. Noordeen F, Vaillant A, Jilbert AR. Nucleic acid polymers prevent the establishment of duck hepatitis B virus infection in vivo. Antimicrob Agents Chemother. 2013;57:5291-8.

17. Bazinet M, Pantea V, Cebotarescu V, Cojuhari L, Jimbei P, Vaillant A, et al. Significant reduction of HBsAg and HDV RNA by the nucleic acid polymer REP 2139 in Caucasian patients with chronic HBV/ HDV co-infection. J Hepatol. 2015;62:S257-8 (Abstract LO2).

18. Jansen L, Vaillant A, Stelma F, Kootstra NA, Bazinet M, AlMahtabet M, et al. Serum HBV-RNA levels decline significantly in chronic hepatitis B patients dosed with the nucleic-acid polymer REP 2139-Ca. J Hepatol. 2015;62:S250 (Abstract O114).

19. Deres K, Schroder CH, Paessens A, Goldmann S, Hacker HJ, Weber O, et al. Inhibition of hepatitis B virus replication by druginduced depletion of nucleocasids. Science. 2003;299:893-6.
20. Wu G, Liu B, Li J, Arzumanyan A, Clayton MM, Schinazi RF, et al. Preclinical characterization of GLS4, an inhibitor of hepatitis B virus core particle assembly. Antimicrob Agents Chemother. 2013;57:5344-54.

21. Klumpp K, Shimada T, Allweiss L, Volz T, Luetgehetman M, Flores $\mathrm{O}$, et al. High antiviral activitiy of the $\mathrm{HBV}$ core inhibitor NVR 3-778 in the humanized UPA/SCID mouse model. J Hepatol. 2015;62:S250 (Abstract O115).

22. Korolowicz K, Czerwinski S, Iyer R, Skell J, Yang J, Tucker R, et al. Antiviral efficacy and induction of host immune responses with SB9200, an oral prodrug of the dinucleotide SB 9000, in the woodchuck model of chronic hepatitis B (HBV) infection. J Hepatol. 2015;62:S557 (Abstract P0636).

23. Benetatos CA, Mitsuuchi Y, Burns JM, Meiman EM, Condon SM, Yu G, et al. Birinapant (TL32711), a bivalent SMAC mimetic, targets TRAF2-associated cIAPs, abrogates TNF-induced NF- $\mathrm{KB}$ activation, and is active in patient-derived xenograft models. Mol Cancer Ther. 2014;13:867-79.

24. Lanford RE, Guerra B, Chavez D, Giavedoni L, Hodara VL, Brasky KM, et al. GS-9620, an oral agonist of toll-like receptor-7, induces prolonged suppression of hepatitis B virus in chronically infected chimpanzees. Gastroenterology. 2013;144:1508-17.

25. Gane EJ, Lim YS, Gordon SC, Visvanathan K, Sicard E, Fedorak RN et al. The oral toll-like receptor-7 agonist GS-9620 in patients with chronic hepatitis B virus infection. J Hepatol. 2015;63:320-8.

26. Perales MA, Goldberg JD, Yuan J, Koehne G, Lechner L, Papadopoulos EB, et al. Recombinat human interleukin-7 (cyt107) promotes T-cell recovery after allogeneic stem cell transplantation. Blood. 2012;120:4882-91.

27. Mackall CL, Fry TJ, Ronald E, Gress RE. Harnessing the biology of IL-7 for therapeutic application. Nat Rev Immunol. 2011;11:330-42.

28. Gaggar A, Coeshott C, Apelian D, Rodell T, Brain R, Armstrong BR, Shen G, et al. Safety, tolerability and immunogenicity of GS4774, a hepatitis Bvirus-specific therapeutic vaccine, in healthy subjects: a randomized study. Vaccine. 2014;32:4925-31.

29. Martin P, Dubois C, Jacquier E, Dion S, Mancini-Bourgine M, Godon $\mathrm{O}$ et al. TG1050, an immunotherapeutic to treat chronic hepatitis $\mathrm{B}$, induces robust $\mathrm{T}$ cells and exerts an antiviral effect in HBV-persistent mice. Gut 2014 (epub ahead of print).

30. Lelu K, Evlachev A, Kratzer R, Dion S, Mancini-Bourgine M, Godon $\mathrm{O}$, et al. TG1050, a novel immunotherapeutic to treat chronic hepatitis $\mathrm{B}$ can control HBsAg and provoke HBsAg seroconversion in HBVpersistent mouse models. J Hepatol. 2015;62:S205 (Abstract O031).

31. Sebestyén MG, Wong SC, Trubetskoy V, Lewis DL, Wooddell CI. Targeted in vivo delivery of siRNA and an endosome-releasing agent to hepatocytes. Methods Mol Biol. 2015;1218:163-86.

32. Keeffe EM, Rossignol JF. Treatment of chronic viral hepatitis with nitazoxanide and second generation thiazolides. World $\mathbf{J}$ Gastroenterol. 2009;15:1805-8.

33. Lucifora J, Xia Y, Reisinger F, Zhang K, Stadler D, Cheng X, et al. Specific and nonhepatotoxic degradation of nuclear hepatitis B virus cccDNA. Science. 2014;343:1221-8.

34. Richman DD. The impact of drug resistance on the effectiveness of chemotherapy for chronic hepatitis B. Hepatology 2000; 32:866-7.

35. Sarrazin C, Kieffer TL, Bartels D, Hanzelka B, Müh U, Welker $\mathrm{M}$, et al. Dynamic hepatitis $\mathrm{C}$ virus genotypic and phenotypic changes in patients treated with the protease inhibitor telaprevir. Gastroenterology. 2007;132:1767-77.

36. Suzuki Y, Ikeda K, Suzuki F, Toyota J, Karino Y, Chayama K, et al. Dual oral therapy with daclatasvir and asunaprevir for patients with $\mathrm{HCV}$ genotype $1 \mathrm{~b}$ infection and limited treatment options. J Hepatol. 2013;58:655-62. 